\title{
Promoting natural fiber from bark of Hibiscus tiliaceus as rope to reduce marine pollution from microplastic fiber yield from synthetic rope
}

\author{
I Wayan Surata ${ }^{1}$, Tjokorda Gde Tirta Nindhia ${ }^{1, *}$, Dwiki Marsetio Widagdo ${ }^{1}$ \\ ${ }^{1}$ Study Program of Mechanical engineering, engineering Faculty, Udayana University, Jimbaran, Bali, 80361, Indonesia
}

\begin{abstract}
Synthetic ropes are popular for application in marine boat as docking, anchor, tow, and sailing. The advantages of synthetic ropes are waterproof, strong and durable, can be designed for sinks or floats and able to stretches. Synthetic ropes are stronger, more resistant to rotting than ropes created from natural fibers. Synthetic ropes also possess certain disadvantages of slipperiness, and can be damaged more easily by UV light. Synthetic ropes is recognizes as a source of microplastic fiber pollutant in marine area. In this work a bark of Hibiscus tiliaceus three is introduced as candidate source of natural fiber for rope to reduce number of microplastic fiber pollutant from synthetic rope. The bark was taken from a trunk with diameter around $20 \mathrm{~cm}$. The bark was immersed in water for 7 days and subsequently was soaked in $5 \% \mathrm{NaOH}$ solution for 2 hours. Fiber obtained then was dried. It was prepared 7 valid single fiber samples. The average of tensile strength of single fiber obtained by using this method is found around $44.604 \mathrm{MPa}$. The average of Modulus elasticity E is found $365.864 \mathrm{MPa}$. The failure strain is found $11.6 \%$.
\end{abstract}

\section{Introduction}

The semi-mangrove plant Hibiscus tiliaceus belonging to the genus Hibiscus (family Malvaceae) is widely distributed in Philippines, Pacific Islands, Southeastern Asia, the South Sea Islands and India. As a Chinese medicine, it is used as heat-clearing and detoxifying, stasis-dissipating and detumescence agents in folk medicine [1]

Hibiscus tiliaceus is a tree that can grow with spreading top with 3-10 meters high with brown or gray bark. The tree grows well along brackish-watered rivers, mangrove forests, and the sea side. Its flowers almost all year round. The trunk is used for canoe in fishery as well as wood fire. The bark is used for making rope. The tree is recognized as ornamental tree [2]. Previous result [2] inform the tensile strength of the single fiber in Newton unit $(\mathrm{N})$ that not involving cross section area of the single fiber that make difficult to be implemented in design. Previous researcher using time to grow as a variable to investigate the effect of tensile strength of the single fiber [2] which is about time consuming and not certain about final condition of the grow after certain time due to disease and as well as climate and environmental impact.

Hibiscus tiliaceus has various beneficial aspects. For example, the leaf can be a laxative medicine. its leaf can also be used for medicine to cure wounds as well as and chronic wounds when applied. Its shell (skin) has a quality to induce vomiting. Its flower can be boiled with milk to cure ear symptoms. Its root has a property when extracted from it to cure colds. Its mucilage from the shell is helpful for curing alimentary canal symptom.
Additionally, its fibers gained from the shell can be used to make robe and paper [3].

The Hibiscus tiliaceus also useful in advance application such as for Green synthesis of $\mathrm{Pd} / \mathrm{Fe} 3 \mathrm{O} 4$ nanocomposite. Palladium nanoparticles were immobilized on the surface of $\mathrm{Fe} 3 \mathrm{O} 4$ using Hibiscus tiliaceus extract as a stabilizing and reducing agent [4]

Because environmental awareness it has the need for natural and eco-friendly construction, formed from textile materials. Hibiscus tiliaceus are readily available in fibrous form, and can easily be extracted from the plant stem itself. This plant grows naturally, with low maintenance costs [3].

Microplastics are widespread emerging contaminants that have, been found globally in the marine and freshwater environments. Microplastics can enter the aquatic environment as, both primary and secondary microplastics from aquatic and, land-based sources [5].

Synthetic ropes are popular for application in marine boat as docking, anchor, tow, and sailing. The advantages of Synthetic ropes are waterproof, strong, durable, can be designed for sinks or floats and able to stretches. Synthetic fibre ropes are stronger, more resistant to rotting than ropes created from natural fibers, synthetic rope also possess certain disadvantages of slipperiness, and can be damaged more easily by UV light. Synthetic fiber ropes is recognized as a source of microplastic fiber pollutant in marine area.

It is the purpose of this work to introduce of bark of Hibiscus tiliaceus as a source of fiber to produce natural rope to replace synthetic rope in marine boat application

* Corresponding author: nindhia@yahoo.com 
since synthetic rope as source of microplastic pollutant in the ocean

\section{Experimental}

The bark of Hibiscus tiliaceus was taken from trunk with diameter around $20 \mathrm{~cm}$. the bark was soaked in water for 7 days continued with soaked in alkali $(5 \% \mathrm{NaOH})$ for 2 hours with gently stirring until the fiber well separated. selection of this $5 \%$ concentration of $\mathrm{NaOH}$ base on result from previous solution research indicated that with concentration $5 \% \mathrm{NaOH}$ resulting the highest surface roughness comparing to other higher concentration $(10 \%$, $15 \%$ and 20\%) [6]. The fiber obtained was washed with water and was dried in the oven at $90^{\circ} \mathrm{C}$. The diameters of single fiber of each tested material were measured. Optical microscope was used to measure the diameter of the single fiber. The diameter measurements were performed on single fiber at three different equidistant points of the fiber. The average of the fiber diameter represented the mean diameter value for each single fiber that was investigated

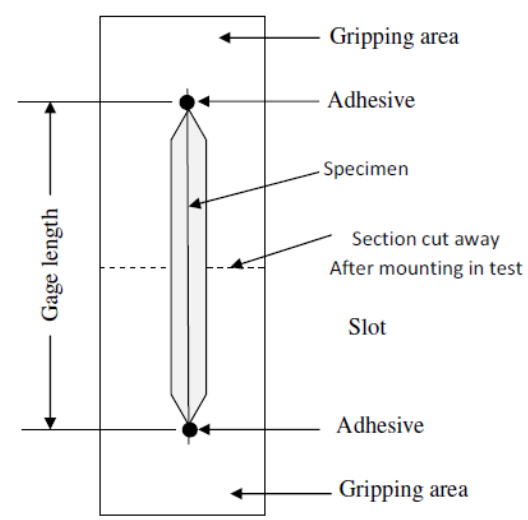

Fig. 1. Single fiber of bark of Hibiscus tiliaceus arrangement for tensile test

The tensile strength test analysis has been carried out following standard test method for tensile strength and modulus of elasticity of fiber ASTM C 1557-03 [7]. Tensile test has been performed to evaluate the tensile strength, modulus elasticity, and strain $(\epsilon)$ of coconut single fiber. Seven times repetition of valid tensile tests were conducted. The average value of tensile test will be provided. A mounting tab (Fig. 1) is used for specimen mounting. Suitable adhesive was placed on the mounting tab with define gage length. The fiber is bond to the mounting tab. The gauge length in this research is $50 \mathrm{~mm}$.

The tensile strength test analysis has been carried out following standard test method for tensile strength and modulus of elasticity of fiber ASTM C 1557-03 [7]. Tensile test has been performed to evaluate the tensile strength, modulus elasticity, and strain $(\epsilon)$ of coconut single fiber. Seven times repetition of valid tensile tests were conducted. The average value of tensile test will be provided. A mounting tab (Fig. 1) is used for specimen mounting. Suitable adhesive was placed on the mounting tab with define gage length. The fiber is bond to the mounting tab. The gauge length in this research is $50 \mathrm{~mm}$.

The tensile strength $(\sigma)$ was calculated by using Equation 1. Where $\mathrm{F}$ is force to failure $(\mathrm{N}), \mathrm{A}$ is a cross sectional area fracture plane normal to fiber axis $\left(\mathrm{m}^{2}\right)$. The tensile strain $(\epsilon)$ was measure by using Equation 2 [7].

$$
\sigma=\frac{\mathrm{F}}{\mathrm{A}}
$$

The tensile strain $(\epsilon)$ was measure by using Equation 2 . Where $\Delta l$ is an elongation of the gage length $(\mathrm{mm})$ and $1_{0}$ is the gage length $(\mathrm{mm})[7]$.

$\epsilon=\frac{\Delta \mathrm{l}}{\mathrm{l}_{0}}$

Fiber Young's modulus was calculated by using Equation 3 [7]

$$
\mathrm{E}=\frac{\sigma}{\mathrm{E}}
$$

\section{Results and discussion}

The Hibiscus tiliaceus fiber can be released from the bark of the trunk by alkali treatment as introduced in this research. The release is caused by reaction of the alkali solution with lignin and hemicelluloses as reported in previous publication [6]. The result of tensile test for single fiber of Hibiscus tiliaceus that was treated with alkali treatment $(5 \% \mathrm{NaOH})$ is presented in Fig. 2 and the value can be found in Table 1. For all 7 samples that are tested, all reveal linier elastic properties with no indication as ductile fiber. The appearance of single fiber is presented in Fig.3. The average tensile strength is found about $44.604 \mathrm{MPa}$ with average failure strain $11.6 \%$. The Average of modulus elasticity (E) is 365.864 $\mathrm{MPa}$. The tensile strength and failure strain that is obtained in this research were found lower than coconut fiber [6].

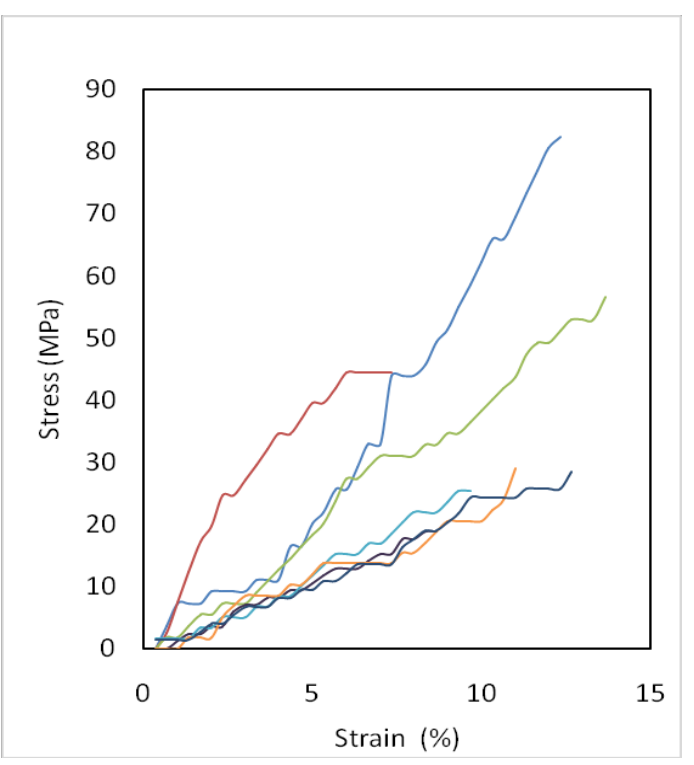

Fig. 2. Graph of stress-strain curves of 7 single fiber of bark of Hibiscus tiliaceus with alkali treatment 
Table 1. The averages of tensile strength, maximum strain and Modulus Elasticity of single fibers of bark of Hibiscus tiliaceus with alkali treatment $(5 \% \mathrm{NaOH})$

\begin{tabular}{|c|c|c|c|}
\hline Sample & $\begin{array}{c}\text { Tensile } \\
\text { strength } \\
(\mathrm{MPa}\end{array}$ & $\begin{array}{c}\text { max. strain } \\
\%\end{array}$ & $\begin{array}{c}\text { Modulus } \\
\text { elasticity } \\
(\mathrm{MPa})\end{array}$ \\
\hline 1 & 82.369 & 12.3 & 667.854 \\
\hline 2 & 71.603 & 14.0 & 511.449 \\
\hline 3 & 56.539 & 13.6 & 413.697 \\
\hline 4 & 18.825 & 8.6 & 217.21 \\
\hline 5 & 25.311 & 9.6 & 261.84 \\
\hline 6 & 29.088 & 11.0 & 264.43 \\
\hline 7 & 28.446 & 12.6 & 224.57 \\
\hline Averages & 44.604 & 11.6 & 365.864 \\
\hline
\end{tabular}

Previous result [2] informed that the tensile strength of the single fiber in unit of Newton $(\mathrm{N})$ that not involving cross section area of the single fiber that make difficult to be implemented in design.

The fiber can be released from bark of Hibiscus tiliaceus by alkali treatment as introduced in this research. The release is caused by reaction of the alkali solution with lignin and hemicelluloses as reported in previous publication [6].

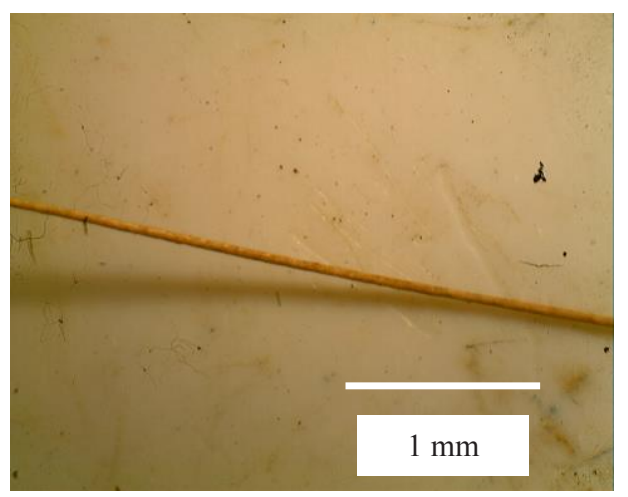

Fig. 3. Appearance of single fiber obtained from bark of Hibiscus tiliaceus

It has been discovered that amphipods, lugworms, barnacles and mussels all ingest microplastics when present in their environments [8,9]. The danger lies in the fact that microplastics are ingested by a variety of marine biota, and have the potential to translocate these harmful constituents to organisms [10]. Primary plastics were made of hydrophobic materials. Plastics were made of chemical materials of polycyclic aromatic hydrocarbon, polychlorinated biphenyl, rganochlorine pesticides, polybrominated diphenyl ethers, alkylphenol, bisphenol and petroleum hydrocarbon, that may cause chronic effects to human health by deterioration of human immune and endocrine disruption. The examined commercial fishes containing microplastics could be a route for transportation of toxic chemical into human via their consumption. microplastics ingestion by fishes becomes the global concern due to their threat to human health [11]. Therefore it is suggested to replace the use of synthetic rope that can be a source of microplastic. The fiber obtained from bark of Hibiscus tiliaceus can be a solution toavoids accumulation of microplastic in the ocean.
Table 2. Tensile strength of various natural and synthetic fiber [12]

\begin{tabular}{|c|c|c|}
\hline Fiber & $\begin{array}{c}\text { Tensile } \\
\text { strength } \\
\text { (MPa }\end{array}$ & $\begin{array}{c}\text { max. strain } \\
\%\end{array}$ \\
\hline Ramie & $400-939$ & $2.0-3.8$ \\
\hline Flax & $345-1830$ & $1.2-3.2$ \\
\hline Hemp & $550-1110$ & 1.6 \\
\hline Jute & $393-800$ & $1.5-1.8$ \\
\hline Harakeke & $440-990$ & $4.2-5.8$ \\
\hline Sisal & $507-855$ & $2.0-2.5$ \\
\hline Alfa & $188-308$ & $1.5-2.4$ \\
\hline Cotton & $287-800$ & $3.0-10$ \\
\hline Coir & $131-220$ & $15-30$ \\
\hline Silk & $100-1500$ & $15-60$ \\
\hline Feather & $100-203$ & 6.9 \\
\hline Wool & $50-315$ & $13.2-35$ \\
\hline E-glass & $2000-3000$ & 2.5 \\
\hline
\end{tabular}

In comparison with other type of natural fiber and synthetic fiber as can be seen in Table 2, the tensile strength of single fibers of bark of Hibiscus tiliaceus that was investigated in this research is in the range of wool.

The low tensile strength of single fibers of bark of Hibiscus tiliaceus is due to low cellulose content (24.22 $w t \%)$ [13] in the fiber comparing to other natural fiber as can be seen in Table 3.

Table 3. Cellulose contends in the Natural fiber (14)

\begin{tabular}{|l|r|}
\hline \multicolumn{1}{|c|}{ Fiber } & \multicolumn{1}{c|}{$\begin{array}{c}\text { Cellulose } \\
\text { (wt } \%)\end{array}$} \\
\hline abaca & $56-63$ \\
\hline Kenaf & 72 \\
\hline Jute & $61-71$ \\
\hline Hemp & 68 \\
\hline Ramie & $68.6-76.2$ \\
\hline & \\
\hline Coir & $32-43$ \\
\hline Flax & 71 \\
\hline
\end{tabular}

The major problems of natural fibre composite is the hydrophilic nature of the fiber. Chemical treatment on reinforcing fibre can reduce hydrophilic tendency. There are several methods of chemical treatment on natural fiber. This work using alkaline treatment, the most used chemical treatment of natural fibers. The important modification done by alkaline treatment is the disruption of hydrogen bonding in the network structure as can be explained by using Equation 1[15].

$$
\text { fiber }-\mathrm{OH}+\mathrm{NaOH} \rightarrow \text { fiber }-\mathrm{O}-\mathrm{Na}+\mathrm{H}_{2} \mathrm{O}
$$

alkaline processing influences the cellulosic fibril, the degree of polymerization and the extraction of lignin and hemicellulosic compounds [15].

Microplastic debris can be classified into 2 basic groups. Primary microplastics are industrially created particles that are used as additives in commercial formulations. Products incorporating this type of material include exfoliating beads in cosmetics, fragmented polyethylene particles in toothpastes, and synthetic 
micro-additives in paints. Secondary microplastics are fractured plastic remnants created from discarded plastics. This secondary group also includes microfibers, threadlike residues. There is currently a good understanding of the sources and physical processes that contribute to microparticulate pollution in the environment. Industrially engineered microparticle feedstocks end up in ocean and surface waters when mishandled. When discarded macroplastics are exposed to the elements, microfragments can be generated in situ as a result of ultraviolet, thermal, and oxidative weathering. These processes cause embrittlement, which promotes fracturing, embrittled plastics become more susceptible to physical abrasion and mechanical fragmentation [16].

Hibiscus tiliaceus tree grows well along the seaside, brackish-watered rivers or canals like mangrove forests and it flowers almost all year round. In terms of use, the tree is ornamental while the trunk is used for fire or canoe making and in fishery and the bark is used for making rope [2]. It is suggested to use bark of Hibiscus tiliaceus to replace synthetic rope to reduce microplastic fiber pollutant in the ocean

\section{CONCLUSIONS}

It is introduced fiber from the bark of Hibiscus tiliaceus for the purpose of replacement of synthetic rope in marine boat application. Synthetic rope is known as source of microplastic pollution in the ocean. The average of tensile strength of single fiber obtained by using this method is found around $44.604 \mathrm{MPa}$. The average of Modulus elasticity $\mathrm{E}$ is found $365.864 \mathrm{MPa}$. The failure strain is found $11.6 \%$

This research is supported by research grant of Penelitian Grup Riset Udayana of Udayana university under contr act no: 55124/UN14.4.A/LT/2019 for the year of 2019.

\section{References}

1. Z.Z Wang., J. Li., X.L.Tang, ,G.Q. Li. Chinese Journal of Natural Medicines 9,3,( 2011)

2. T. Arrak, S. Boonyobhas., S. Chonsakorn and R. Mongkholrattanasit, Textiles \& Fashion, Bangkok T hailand, (2012)
3. S. Chonsakorn, B.,R. Mongkholrattanasit, K. Pholam, P. Parsapratet and T. Arrak, Materials Science Forum, . 857, (2016)

4. M. Nasrollahzadeh, Z. Issaabadi, S. M. Sajadi,, Separation and Purification Technology, 197 (2018)

5. S. Ziajahromi, A. Kumar, P. A. Neale, and F. D. L. Leusch, , Environ. Sci. Technol. 51,(2017)

6. M. Arsyad, ARPN Journal of Engineering and Applied Sciences, 12, 6 (2017)

7. ASTM C 1557 -03, ASTM international, PA, United State(2003)

8. R.C.Thompson, Y Olsen,R.P. Mitchell, A. Davis, ., S.J. Rowland, A.W.G. John, , D. McGonigle,, A.E. Russell, Science,838, 304(2004)

9. M.A. Browne,A. Dissanayake, T.S. Galloway, M.D.Lowe, R.C. Thompson., Environ. Sci. Technol. 42,13(2008)

10. V. Hidalgo-Ruz, L. Gutow., R.C. Thompson, M. Thiel, Environ. Sci. Technol. 46,6, (2012)

11. 11 A.R. Hastuti, D.T.F. Lumbanbatu, Y. Wardiatno, Biodiversitas, Volume 20, Number 5, May 2019, Pages: 1233-1242

12. S.Sendhil Kumar, V. Anbumalar, International Journal of Innovative Science, Engineering \& Technology, Vol. 2 Issue 11, November 2015.pp 929-939

13. W. A. Wirawana, S. A. Setyabudi, T. D. Widodo, M.. A. Choiron, JEMMME, Vol.2, No. 2, November 2017, pp.98-105

14. M. A. Usmani, M.Anas, IOP Conf. Series: Materials Science and Engineering 404 (2018) 012048, pp.1-5

15. M. Ravi, R. R. Dubey, A. Shome, S. G.C. A. Kumar, IOP Conf. Series: Materials Science and Engineering 376 (2018) 012053, pp. 1-5

16. Steve A Carr, Integrated Environmental Assessment and Management — Volume 13, Number 3, 2017, pp. 466-469 